A BLEAK OUTLOOK

HIV/AIDS and the South African Police Service

\author{
Martin Schönteich \\ ant@iss.co.za
}

As yet largely unrecognised by South African criminal justice policy makers, HIV/AIDS could significantly impact on the country's criminal justice system agencies, especially the police. South Africa's HIV/AIDS epidemic is likely to result in a change in the demand for the quantity and complexity of services required of the South African Police Service. Simultaneously, the capacity of the police to deliver an adequate service will be undermined as an increasing number of police officers succumb to the epidemic.

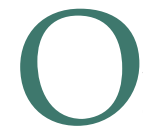
ne of the consequences of AIDS for South Africa will be an increase in the proportion of adolescents and young adults relative to the general population. This larger youthful population could result in more delinquent behaviour, predatory crime and inter-group conflict.

The rapidly increasing number of AIDS orphans in the country, and the poverty associated with this phenomenon, could bring about a rise in property crime. Moreover - and this is an issue which requires more research - it is possible that less resilient orphans who experience social exclusion, abuse and victimisation will be at greater than average risk of becoming antisocial individuals and even violent offenders. ${ }^{1}$ Many orphans will themselves be vulnerable to criminal victimisation. In combination with sluggish AIDS-impeded economic growth, and drastically decreased adult longevity, this could result in changed offending patterns and higher crime levels.

The 'demand side' problems of the South African Police Service (SAPS), having to deal with higher and new forms of crime, will be compounded on the 'supply side' as the ability of the police to provide an effective service is undermined by HIV/AIDS.
With an increasing number of HIV-positive police officers falling ill and dying, impacting on the availability of experienced personnel, the ability of the police to prevent, investigate and respond to crime could be substantially diminished. In a few years' time this could significantly reduce the levels of service the SAPS is able to provide.

\section{AIDS in South Africa}

HIV/AIDS is the most prevalent and destructive epidemic to occur in South Africa's recorded history. Annual surveillance conducted by the South African Department of Health has shown that among pregnant women attending public health clinics for antenatal care, the HIV sero-prevalence rate has increased from less than $1 \%$ in 1990 to $25 \%$ in 2001.

South Africa is said to have more people living with HIV than any other country. At the end of 2002 the country had a population of some 46 million people, of which an estimated 6.5 million were infected with HIV. By the year 2010 the cumulative number of AIDS deaths is expected to exceed six million. ${ }^{2}$ It is estimated that HIV prevalence will peak at just over $16 \%$ of the total population in 2006, with 7.7 million people infected. 
An HIV-positive person typically passes through four stages of infection, according to the World Health Organisation's staging system. Those in the first two stages of infection are relatively a-symptomatic, those in stage three suffer weight loss and spells of illness from opportunistic infections, and those in the fourth stage have full-blown AIDS. A person not receiving treatment will usually die within 12-18 months of reaching the fourth stage.

In mid-2002 just over half (55\%) of HIV-positive South Africans were in the first stage of infection. A further $20 \%$ were in the second stage, $18 \%$ in the third stage, and $7 \%$ in the fourth stage with fullblown AIDS. With less than a tenth of HIV-positive people in South Africa having reached the fourth stage of infection, the impact of the epidemic has been moderate so far. Much of the impact will only be experienced towards the end of the decade.

\section{Estimating HIV/AIDS prevalence in the police}

In 2000 the SAPS launched a five-year strategic plan to combat HIV/AIDS. The plan is informed by an impact study of HIV/AIDS in the SAPS that was conducted in 1998/99. According to the impact study, which was based on modelling using HIV/AIDS and demographic data available at the time, "a maximum of $8 \%(8,520)$ to $10 \%(10,649)$ of functional police officers might be infected with HIV". ${ }^{3}$ (Functional officers are uniformed personnel and police investigators or detectives, not civilian personnel.) Based on the impact study, the SAPS' strategic plan makes some alarming predictions about expected police HIV prevalence levels in 2015:

The overall percentage of POLMED [the compulsory in-house medical aid scheme for functional members of the SAPS] principal members infected with HIV will increase from $8 \%$ in 2000 to $14 \%$ by 2015 (one out of seven members will be infected). Age-specific prevalence projections indicate that HIV prevalence amongst 25 to 29 year-olds, and 30 to 34 year-olds, is expected to increase from $15 \%$ to $17 \%$ in 2000 , to approximately $35 \%$ and $45 \%$ respectively by $2015 .{ }^{4}$

The impact HIV/AIDS may have had on the SAPS so far can be deduced from the significant increase in the proportion of employees who have left the Department of Safety and Security because of death or on account of ill health. (SAPS employees make up the vast majority of the department's personnel.) In 1998/99, 1,848 employees per 100,000 left the department because of death or as a result of being discharged on account of ill health. By 2000/01 this had increased to 2,179 per 100,000 employees (or one out of every 46 employees) - an increase of $18 \%$ over three years (Figure 1).

Figure 1: Number of deaths and discharges due to ill health, per 100,000 employees of the Department of Safety and Security

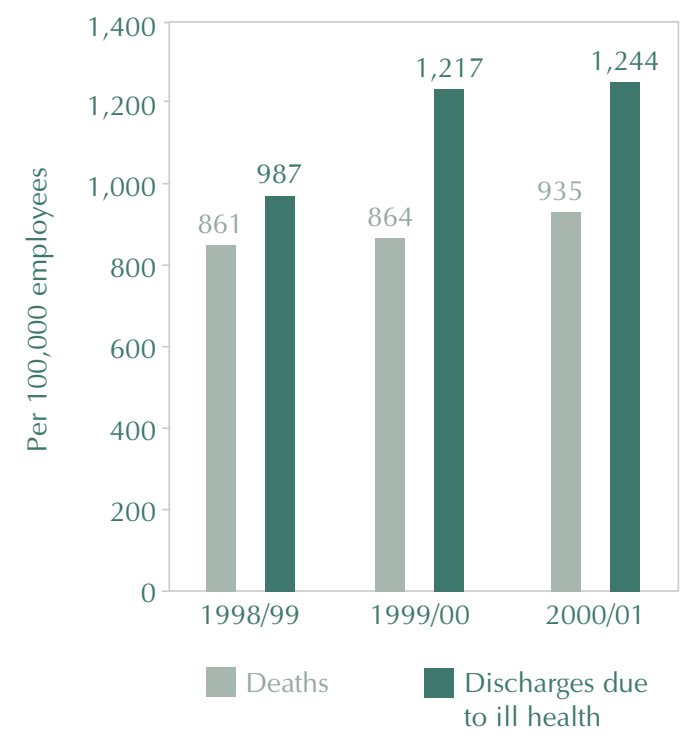

Source: SAPS 2001/02 Annual Report

While not all deaths and discharges due to ill health in the Department of Safety and Security are related to HIV/AIDS, the significant increase over this period probably is.

There are significant differences in prevalence among different race groups in South Africa. It is expected that HIV prevalence will peak at $3.2 \%$ (in 2011) for whites, at $4.8 \%$ (2010) for Asians, at $6 \%$ (2010) for coloureds and at $19.5 \%$ (2006) for blacks. ${ }^{5}$ It is consequently informative to break down the functional police personnel within the SAPS by race so as to permit a more accurate estimate of the likely prevalence rate within the organisation. 
In January 2003 almost two-thirds (62\%) of all functional police personnel in the SAPS were black, a quarter (25\%) white, 9\% coloured and 4\% Indian. Among commissioned officers the proportions were as follows: white $(48 \%)$, black $(38 \%)$, coloured $(8 \%)$ and Indian (6\%). Compared to their proportion of the general population, whites and to a lesser extent Indians are over-represented in the SAPS. This could imply that average prevalence levels in the police are somewhat below the national average - especially among commissioned officers, of which 54\% are white or Indian (Figure 2).

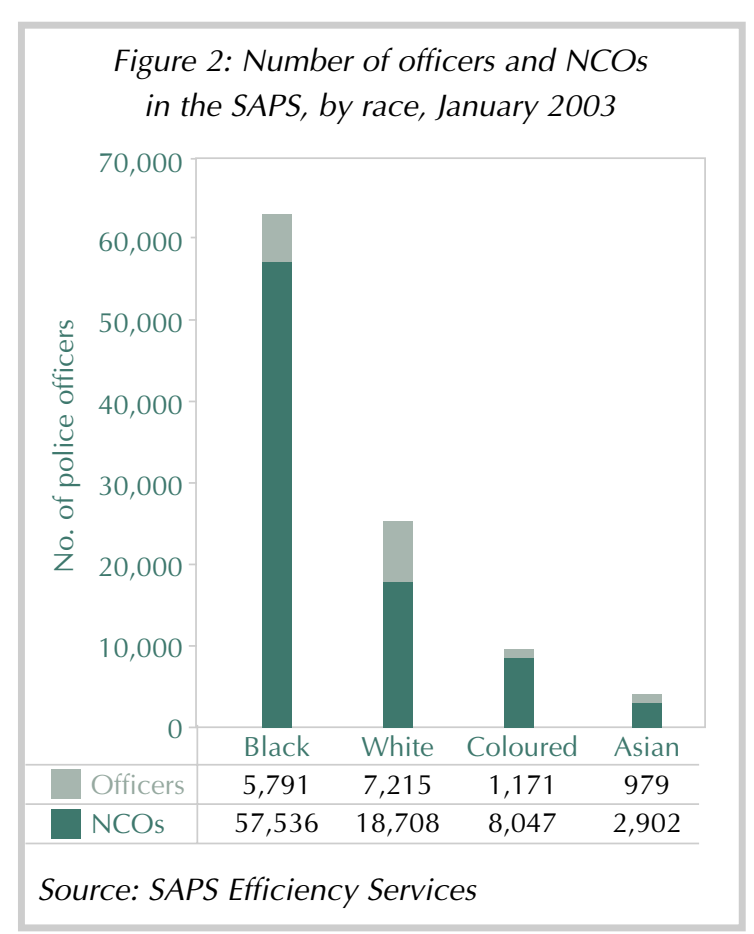

Notwithstanding the racial composition of the SAPS, other factors particular to the police environment raise the risk of HIV infection among SAPS members. According to UNAIDS:

Uniformed services are a highly vulnerable group to sexually transmitted infections (STIs) mainly due to their work environment, mobility, age and other facilitating factors that expose them to higher risk of HIV infection. Among male population groups studied, military and police in many countries generally report higher levels of HIV/AIDS infection than the national average.
In South Africa police officers may spend lengthy periods away from home on special duties. These could include border control duties, tactical deployment such as policing major public events or responding to an emergency such as the wave of urban terror that plagued the Western Cape in the late 1990s, or to attend training courses. ${ }^{7}$ As a result some police officers may be tempted to look for ways to relieve loneliness, boredom, stress and the build-up of sexual tension.

Moreover, many male SAPS officers are in a highrisk age group for HIV infection - the sexually active 25-35 year age group. Relatively low levels of maturity combined with high levels of testosterone among this age group boosts aggression and the willingness to take risks. These traits are further enhanced by the paramilitary culture that still pervades some sections of the SAPS - such as the public order units, dog units, crime prevention units and the flying squad - which encourages aggression and risk-taking as important characteristics of effective 'crime fighters'. Outside of work this can lead to risky sexual behaviour such as purchased sex and sex without a condom.

In South Africa this may be abetted by the fact that police officers, particularly those stationed in rural areas, often have more disposable income than most of the local population around them.

(According to one indicator of poverty unemployment - South Africa had an official unemployment rate of $37 \%$ in 2001.) This provides police officers with the financial means to purchase sex on an on-going basis, facilitated by the fact that police officers, due to the nature of their work, frequently interact with sex workers.

The nature of their work also exposes police officers to risk of infection not involving sexual intercourse. For example, during the course of an arrest police officers are at risk of being injured and bitten, which can lead to the transmission of the HI-virus. An indication of the risks police officers face can be gleaned from the high number who are killed every year. Since 1994 an average of just over 200 police officers have been killed per year. On average SAPS members are about three-and-a-half times as likely to be killed than South Africans in general. ${ }^{8}$ 


\section{Interpretation}

Based on national HIV prevalence estimates, the police's 1998/99 HIV impact assessment, the work environment of the typical police officer, and the age, gender, race and socio-economic composition of SAPS officers, it is likely that prevalence levels among police officers are somewhat higher than the South African adult average. Prevalence levels should, however, be significantly lower among commissioned officers, who make up $15 \%$ of all functional police personnel. This is because of their higher average age, racial profile, and relatively high educational qualifications (HIV prevalence in South Africa tends to decline with higher education and income levels). ${ }^{9}$

Prevalence levels in the police are likely to vary significantly between provinces. It is reasonable to conclude that, as with prevalence levels among the general population, police officers in the provinces of KwaZulu-Natal, Mpumalanga, Free State and Gauteng will exhibit above average HIV prevalence levels compared to those in the SAPS as a whole. This is a significant point to make as police officers in these four provinces comprise $53 \%$ of the country's functional police personnel.

\section{Impact}

Over the next decade political pressure on the South African government to devote more resources to health and welfare services, is likely to increase. This, and the negative effect the HIV/AIDS epidemic will have on the economy generally, is likely to curtail the fairly generous budgets the treasury has allocated to the criminal justice system in the past.

HIV/AIDS on an epidemic scale can detrimentally affect the capacity of government institutions. AIDS can decimate the ranks of skilled administrators, diminish the reach or responsiveness of government institutions, or reduce their resilience. HIV/AIDS is likely to have, among others, the following consequences for the SAPS:

- Increased absence from work and worker attrition as people fall ill and take sick leave, or require time off work to care for sick relatives.

Police services in remote areas and disadvantaged communities may be particularly vulnerable to absenteeism or death among staff, because of shortages of skilled staff and acute resource constraints.

- Productivity will decline because of time off and the deteriorating health of HIV-positive employees.

- Morale may decline as many employees are affected by HIV/AIDS either through illness and death among close family members and colleagues, or themselves being infected.

- The average age and experience level among police employees will fall, with negative implications for institutional memory and coherence.

- Higher recruitment and training costs can be expected.

A study conducted at a KwaZulu-Natal sugar mill found that in the two years prior to HIV-positive employees taking retirement on account of illhealth, an average of almost 28 days were lost in each year as a result of sick-leave, hospitalisation and clinic visits. ${ }^{10}$ Taking into account estimates for lost wages (due to lost days), the costs of hiring and training replacement workers, and limited clinic and hospital-related costs, it has been estimated that the cost of each HIV infection is roughly three times the annual salary in each of the final two years of employment. The study made no adjustment for increased pension or medical aid costs as over $90 \%$ of the HIV-positive workers were in the lowest skill bands.

In the case of the SAPS the cost of each HIV infection is likely to be higher, as police officers make use of employer-based pension and medical aid plans. Moreover, most police officers have relatively high skill levels, which are expensive to replace. Good investigation and detection techniques are also difficult to teach in a classroom environment, and are usually honed through practical experience in the field. Once lost, such skills can take years to replace.

Partly to meet ambitious affirmative action targets, and to increase the proportion of officers in higher rank-related salary categories, police personnel numbers at middle and higher management level are unhealthily high. There is almost one commissioned officer (of the rank of captain and 


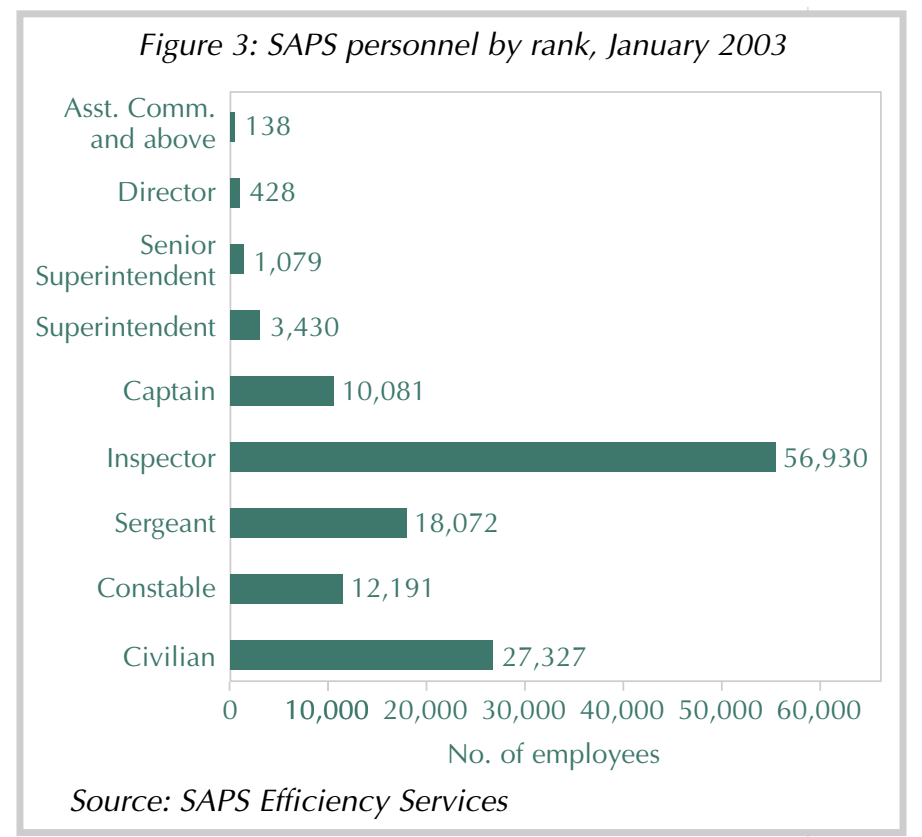

While the SAPS' present personnel recruitment drive (whereby an additional 30,200 entry-level constables are to be employed by early 2006) may offset the AIDS-related losses among NCOs to a certain extent, there will invariably be a decline in the average experience level of police officers.

Policing and detective work is largely practically orientated. It requires the ability to understand and interpret human behaviour, to think logically, to sum up the demeanour and expression of crime suspects quickly and correctly, and to identify and collect various forms of evidence in such a manner that the prosecution service can build up a convincing and coherent case in court. Many of these skills cannot easily be taught and are

higher) for every six non-commissioned officers in the SAPS. (See Everyone's an Inspector, Crime Quarterly 1, 2002.) Out of 102,349 functional police officers employed by the SAPS in January 2003, only 12,191 (or 12\%) were constables (Figure 3 ).

The SAPS has nearly five times more inspectors and one-and-a-half times as many sergeants as constables. According to Leggett, such a "distribution is absurd in terms of functional responsibilities". ${ }^{11}$ The South African distribution appears to be the opposite of international policing norms. The result is that there is no real differentiation of function between noncommissioned officers. The virtue of a military-type structure, with every incident having a clear line of responsibility associated with it, is blurred in the SAPS.

In South Africa there tends to be an inverse relationship between HIV prevalence and levels of income and education. Non-commissioned officers (NCOs) are less educated and earn less than commissioned officers, and black people make up a greater proportion of NCOs $(66 \%)$ compared to commissioned officers (38\%). It is consequently likely that AIDS will disproportionately affect the NCO ranks within the police service, thereby exacerbating the already skewed rank structure within the service. acquired and perfected through practice and experience. A rapid staff turnover therefore undermines the professional capacity of the police service.

Moreover, a rapid skills drain, brought about by HIV/AIDS, places additional strains on the shrinking number of experienced officers and detectives. A rapid loss of skills means fewer mentors for new functional personnel, and a concomitant increase in the burden placed on experienced police officers.

\section{Conclusion}

One of the consequences of HIV/AIDS in South Africa is an increase in the proportion of adolescents and young adults to the general population. Adolescent and young adult males are disproportionately likely to commit a range of violent crimes such as murder, rape, assault and robbery.

HIV/AIDS will hamper the South African government's ability to continue providing the levels of service which it provided before the advent of widespread AIDS. As more resources will invariably be channelled into the health and welfare sectors to ease some of the impact of the HIV/AIDS epidemic, fewer resources will be available for crime prevention, crime combating and the police service generally. 
Many of these developments are inevitable unless an inexpensive and easy to administer cure for HIV/AIDS is found. The government and the SAPS are, however, not powerless to mitigate some of the impact HIV/AIDS will have on the operational capacity of the SAPS. Initiatives such as multiskilling training courses for both new recruits and existing personnel, proper record-keeping to archive the police service's institutional memory, and outsourcing of some labour-intensive police functions, could be used to reduce the most adverse consequences HIV/AIDS may have on the SAPS.

\section{Endnotes}

1 M Schönteich, The coming crime wave? AIDS, orphans

and crime in South Africa, Southern African Journal of HIV Medicine, March 2002.

2 R Dorrington, D Bourne, D Bradshaw, R Laubscher and I M Timaeus, The impact of HIV/AIDS on adult mortality in South Africa, South African Medical Research Council, Cape Town, September 2001, p 21.

3 The South African Police Service's five-year strategic plan to combat HIV/AIDS: 2000-2005, Annexure A, SAPS Health Management, South African Police Service, Pretoria, 2000, p 1.

4 Ibid, pp 1-2.

5 N Nattrass, AIDS, Growth and Distribution in South Africa, CSSR Working Paper 7, March 2002, p 4.

6 HIV/AIDS and Uniformed Services, Fact sheet 3, UNAIDS, Geneva, July 2002, p 1.

7 For example during the World Summit on Sustainable Development held in Johannesburg in late 2002, the SAPS deployed some 7,400 officers in and around the venue. The officers were drawn from all nine provinces including head office.

8 S Masuku, Most at risk: Murder of SAPS officials, Nedbank/ISS Crime Index 4(4), July-August 2000, pp 15-16.

9 L Johnson and D Budlender, HIV Risk Factors: A Review of the Demographic, Socio-economic, Biomedical and Behavioural Determinants of HIV Prevalence in South Africa, CARE Monograph 8, January 2002, pp 14-19.

10 C Morris, D Burdge and E Cheevers, Economic Impact of HIV Infection in a Cohort of Male Sugar Mill Workers in South Africa, South African Journal of Economics 68(5), 2000, pp 933-946, as cited in: Nattrass, op cit, p 14.

11 T Leggett, Everyone's an inspector: The crisis of rank inflation and the decline of visible policing, SA Crime Quarterly 1, July 2002, p 23. 